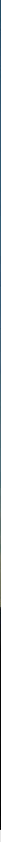

\title{
Temas relacionados en el cine y la literatura
}

\section{CARlos Torcal Tello}

Analista de Sistemas TI, Coritel

Escritor de cuentos

\section{José Miguel GallaRdo}

Unidad de Teledetección Terrestre, Agencia Estatal de Meteorología (AEMET)

Escritor

I myself am deep green and very worried about the future of humankind due to what I see as devastating climate impact events coming down the road in the next 500 years, if we as a world community do not stop $\mathrm{C} 02$ emissions soon. So for me, cli-fi is a fiction genre that might be helpful in waking people up and serving as an alarm bell.

Cli-fi: could a literary genre help save the planet? - DAN BLOOM, editor que acuñó el término Cli-fi, entrevista del periodista DAVID Holmes

Aunque la física del caos en la predicción meteorológica no es abordada como tal, en toda su magnitud, en el cine o en la literatura, los fenómenos meteorológicos han puesto contexto a numerosas obras y, en menor medida, la física del caos aparece en unas cuantas. Con no poco esfuerzo, hemos intentado encontrar un cierto número de referencias en estas formas de arte donde se abordan temas afines a la meteorología o a la teoría del caos y que pueden conectar con algunos aspectos mostrados en este libro. Presentamos así una primerísima y muy sencilla aproximación a unas pocas películas y novelas que tocan, a mayor o menor distancia, temas relacionados con el caos y la meteorología o la climatología y el cambio climático. Ofrecemos una sinopsis de estas obras seleccionadas, así como nuestra modestísima impresión desde el punto de vista técnico-científico.

Palabras clave: meteorología, física del caos y cambio climático en el cine y la literatura, género literario cli-fi.

Imagen parte superior: sol de atardecer y parhelio, a la derecha, entre cirrus fibratus y otras formaciones nubosas. Collado Villalba, hacia el oeste, 23 de enero de 2018. Fotografía de Aurora SAnTOS. 


\section{C.1 Cine}

Carlos torcal Tello

Analista de Sistemas TI, Coritel

Escritor de cuentos

El cine, a lo largo de su historia, ha contado con frecuencia relatos que por lo general tenían la siguiente línea argumental: nos presentaban a los protagonistas y sus proyectos. Todos aparentemente felices y tranquilos. Poco a poco iban pasando cosas que hacían que todo se torciese, incluso se fuera al traste. Pero al final los guionistas lo conseguían arreglar y ponían un final feliz para que los espectadores se fueran contentos y volvieran a pasarse por las salas.

En géneros como el fantástico o el de la ciencia ficción, a veces la propia naturaleza era la causante del desvío del plan inicial, siendo muchas veces el meteorológico un factor clave para estos casos (películas como Twister o El día de mañana son claros ejemplos). Otras veces, el afán desmedido del protagonista en pasar a la posteridad a cualquier precio era la causa del caos en que desembocaba todo. Vienen a la mente clásicos como Jekyll y Hide, La Isla del Doctor Moureau, Los pasajeros del tiempo, El hombre con rayos $X$ en los ojos, El planeta de los simios, etc. Más recientemente, películas como Parque Jurásico o El efecto mariposa, se han ocupado del problema de la imprevisibilidad.

Los viajes en el tiempo son, en este ámbito, un lugar común. La película Timeline plantea un viaje al pasado en el que unos científicos interfieren en un mundo medieval lleno de guerras. En El final de la cuenta atrás, un portaaviones de la marina americana de maniobras por las costas de Hawaii es engullido por una monumental tormenta y desaparece sin dejar rastro alguno. Pasada la tormenta, descubren que han retrocedido en el tiempo hasta el 7 de diciembre de 1941, el día del bombardeo japonés a la base de Pearl Harbour. ¿Se verán afectados el futuro y el presente? Parece lógico pensar que sí. Aunque podría ser un desastre. ¿Qué pasaría si viajásemos al pasado y matásemos a nuestra madre antes de nacer nosotros? La paradoja resulta inevitable: ¿Cómo habríamos podido entonces viajar al pasado sin haber llegado a nacer? La película El sonido del trueno lleva al cine un relato corto de RAY BRADBURY abordado en la sección de literatura de este capítulo y que plantea cuestiones similares. Otras películas plantean viajar en sentido contrario, es decir, hacia el futuro. En Los pasajeros del tiempo, Terminator, o Regreso al Futuro en alguna de sus partes, se va hacia delante en el tiempo para saber qué va a ser de nosotros.

Pero no sólo el género de la ciencia ficción se ha ocupado de problemas relacionados con la incertidumbre y el caos. Películas como Atrapado en el tiempo, Caos o Cuando todo está perdido cuentan historias en las que un hombre racional y metódico, instruido y sobradamente preparado para llevar a buen puerto sus objetivos se ve, por una serie de circunstancias imprevisibles, irremediablemente abocado a situaciones diferentes a lo que esperaba y descubriendo que no se puede controlar el destino. Cuando todo está perdido cuenta la historia de un viejo lobo de mar (ROBERT REDFORD) que navega en solitario por el océano Índico y descubre una mañana al despertarse que el casco de su velero se ha agrietado debido a un choque con un contenedor que flotaba a la deriva. A partir de este momento, todo se tuerce para este hombre que deberá superar todo tipo de problemas si quiere sobrevivir.

Volviendo a la ciencia, como hemos destacado al principio, ésta ocupa muchas veces un importante lugar dentro del cine. Películas como Gravity, Interstellar, Apollo 13 y 2001 Una Odisea en el espacio son muy rigurosas a la hora de cuidar los detalles científicos. Por ejemplo, en ellas no suena ningún ruido de explosiones, disparos ni nada parecido, ya que en el espacio no hay sonido porque no existe aire por el que puedan transmitirse las ondas sonoras. Por tanto tampoco hay oxígeno, por lo que tampoco tienen cabida el fuego de las explosiones o los disparos. Pero no siempre los productores y guionistas aportan todo el rigor científico que sería deseable. En contraposición a los anteriores, filmes como Armageddon o Independence Day se saltan a la torera estos detalles técnicos.

Un ejemplo lo encontramos cuando entra en juego la ingravidez. En Independence Day, los protagonistas salen al espacio a combatir a unos extraterrestres pero no les afecta en nada que no exista gravedad. Ellos siguen caminando tranquilamente por el suelo como si estuvieran en la Tierra. Por el contrario, en 2001 Una Odisea en el espacio, se muestra a la perfección cómo el hombre ha sido capaz de diseñar naves que funcionan con gravedad artificial por medio de la fuerza centrífuga. De esta forma, en la ingravidez del espacio, se ve cómo una nave actúa como el tambor de una lavadora girando sobre sí misma para crear una gravedad artificial y así pegar al suelo los pies de los tripulantes. Esa gravedad artificial, en el contexto de la física, se llama aceleración centrífuga, una aceleración debida al hecho de estar montados sobre un 
sistema de referencia llamado no inercial $[3,5]$.

A continuación desglosamos algunas de las películas que directa o indirectamente tienen relación con el caos, la meteorología o la climatología. Para alguna de ellas hemos añadido el apartado de Aspectos técnicos para apuntar aquellos detalles que nos han llamado la atención desde el punto de vista científico.

El efecto mariposa, de Eric Bress y J. Mackye Gruber.

Título original: The Butterfly Effect

Año: 2004

Director: ERIC BRESS, J. MACKYE GRUBER

Guión: ERIC BRESS, J. MACKYe GRUber

Música: Michael Suby

Reparto: Ashton Kutcher, Amy Smart

Género: Fantástico. Thriller. Drama / Viajes en el tiempo

Sinopsis: Un joven con traumas de infancia, descubre una técnica que le permite viajar atrás en el tiempo y meterse en su cuerpo de niño para poder cambiar el curso de su historia. Sin embargo también descubre que cualquier mínimo cambio en el pasado produce un gran impacto en su futuro.

Aspectos técnicos: esta película plantea la idea de universos paralelos como alternativa a la idea clásica de que solo exista una línea temporal absoluta. Cada vez que un viajero del tiempo viaja al pasado y cambia algo, se crea un universo paralelo que transcurre por su propia línea temporal. De alguna forma se conseguiría evitar posibles paradojas que nos impidieran viajar hacia atrás en el tiempo tal y como comentábamos en la introducción. Sin embargo, plantea un problema diferente, el protagonista puede viajar a su pasado tantas veces como quiera pero el escenario de muchos mundos que se generan da como resultado que, cada vez, termina en una rama diferente de la historia de la que salió. Desde un punto de vista muy libre, se aborda el tema del efecto mariposa (sec. 5.5 en la página 64).
Desafío total, de Paul Verhoeven.

Título original: Total Recall

Año: $\quad 1990$

Director: Paul Verhoeven

Guión: DAN O'BANNON, GARY GOLDMAN (basado en el relato de PHILIP K. DICK)

Música: JERRY GOLDSMITH

Reparto: ARnOld SchWARZENEGGER, SHARON STONE, MichaEL IRONSIDE

Género: Ciencia ficción. Acción

Sinopsis Año 2084. Un hombre tiene un sueño recurrente donde aparece Marte. Decide acudir a una agencia de viajes virtuales para que le implanten en su cerebro una experiencia virtual que se desarrolle en dicho planeta. Pero durante el implante algo falla que le hace darse cuenta de quién es realmente, un agente especial que en su pasado ya vivió en Marte.

Aspectos técnicos: La presión atmosférica superficial de Marte es aproximadamente 1/100 de la de la Tierra. Eso supone que la atmósfera de Marte puede ser considerada, aproximadamente, un vacío. Un humano desprotegido perdería el sentido en cerca de 20 segundos y podría sobrevivir no más de un minuto en la superficie de Marte sin un traje espacial. ¡iPero eso tampoco quiere decir que se te salgan los ojos de las órbitas en pocos segundos!!

\section{El sonido del trueno, de Peter Hyams.}

Título original: A Sound of Thunder

Año: 2005

Director: Peter Hyams

Guión: Thomas Dean Donnelly (Historia: RAY BRADBURY)

Música: Nick GlenNie-Smith

Reparto: Edward Burns, Ben Kingsley, CatHERINE MCCORMACK

Género: Ciencia ficción. Acción. Aventuras I Viajes en el tiempo 
Sinopsis: Año 2054. Los viajes en el tiempo están a la orden del día. La empresa que tiene la patente organiza safaris para cazar dinosaurios prehistóricos. El jefe de la expedición se ocupa de la seguridad de los viajeros. Sin embargo, jugar con el tiempo es muy peligroso y cualquier error puede tener consecuencias devastadoras en el presente.

Aspectos técnicos: BRADBURY se anticipa de alguna manera a LORENTZ (sec. 5.5 en la página 64) quien, años después del relato, acuñó (o recuperó) el término efecto mariposa aplicado a la meteorología. El escritor plantea en su relato que si se viaja al pasado hay que tener cuidado de no dejar ningún objeto allí, no traerse nada, no pisar nada... ya que la menor variación podría tener gran repercusión en el futuro. En este caso el efecto mariposa provocará grandes cambios en el futuro pero en forma de oleadas, mediante lo que denomina como «ondas temporales»; es decir, si algo se ha cambiado en el pasado, el futuro no se verá afectado de inmediato. BRADBURY introduce la atractiva idea de que los cambios llegarán a través de dichas ondas, como cuando tiras una piedra en un estanque.

\section{Twister, de Jan de Bont.}

Título original: Twister

Año: 1996

Director: JAN DE BONT

Guión: Michael Crichton, Anne-Marie MARTIN

Música: MARK MANCINA

Reparto: Helen Hunt, Bill Paxton, Philip SEYMOUR HOFFMAN

Género: Acción I Catástrofes

Sinopsis: Una impresionante tormenta va a llegar a Oklahoma y dos grupos de científicos expertos en tornados se disponen a ser los primeros que obtengan resultados sobre la misma.

Aspectos técnicos: Los tornados generados por ordenador que se muestran en esta película son absolutamente espectaculares y el guión es bastante didáctico, ya que se explica bastante bien al espectador cómo funciona un tornado. No obstante, hay algún detalle técnico no del todo preciso. Por ejemplo, la categoría de un tornado (F3, F5, etc.) no se puede anunciar a priori como ocurre en algún momento de la película. Por el contrario, una vez que ha pasado y que se ha medido la velocidad de los vientos y los destrozos que ocasionados, sí que se puede clasificar. Además, la película transcurre en 1969 y la escala que tipifica los tornados según la daños que provocan (escala Fujita), no se creó hasta dos años después.

\section{Sharknado, de Anthony C. Ferrante.}

Título original: Sharknado

Año: 2013

Director: Anthony C. FerRante

Guión: THUNDER LEVIN

Música: RAMIN Kousha

Reparto: IAN ZIERING, TARA REID, JOHN HEARD

Género: Acción I Catástrofes

Sinopsis: Un tremendo huracán llega a la ciudad de Los Ángeles y provoca devastadores tornados que extraen a los tiburones del mar y los lanzan contra la población.

Aspectos técnicos: La probabilidad de que grandes escualos como los que aparecen en esta película sean levantados por un huracán es francamente baja. Por si fuera poco, se sabe que los tiburones son sensibles a los cambios en la presión, por lo que suelen abandonar el área justo antes de una gran tormenta. Los tiburones pequeños o de medio tamaño migran a otras latitudes y los tiburones de gran tamaño, como el toro o el tiburón blanco, descienden a aguas profundas. Sin embargo, un tornado puede ser el responsable de capturar animales pequeños y ligeros como peces o ranas y dejarlos caer a grandes distancias de su lugar de origen $[2,8]$. 
El final de la cuenta atrás, de Don Taylor.

Título original: The Final Countdown

Año: 1980

Director: DON TAYLOR

Guión: DAVID Ambrose

Música: JoHn ScOTT

Reparto: KIRK Douglas, MARTIN SheEN, KATHARINE ROSS

Género: Ciencia ficción. Fantástico | Viajes en el tiempo.

Sinopsis: Un portaaviones de la marina americana de maniobras por las costas de Hawaii es engullido por una monumental tormenta y desparece sin dejar rastro alguno. Pasada la tormenta, descubren que han viajado hacia atrás en el tiempo. Ahora están a 7 de diciembre de 1941, el día del bombardeo japonés a la base de Pearl Harbor.

Aspectos técnicos: entre la fantasía y la cienciaficción, el delicado tema del viaje al pasado para realizar cambios en el presente se trata con poco rigor, dando prioridad a la acción y el americanismo. No se menciona el efecto mariposa en sí.

Viaje alucinante al fondo de la mente, de Ken Russell.

Título original: Altered states

Año: 1980

Director: KEN RUSSELL

Guión: PADDY CHAYEFSKY

Música: John Corigliano

Reparto: William Hurt, Blair Brown, Bob BALABAN, Charles Haid

Género: Ciencia ficción. Fantástico.

Sinopsis: Un científico está dispuesto a llegar hasta el límite en sus experimentos para descubrir el «verdadero» origen del hombre. Está convencido de que los átomos del cerebro humano tienen memoria y que han ido acumulando información desde el principio de los tiempos. Su propósito es viajar a su propia «memoria molecular» para llegar a descubrir su propia esencia primigenia mucho más cercana a la de los animales y al resto de los seres vivos.

Aspectos técnicos: La película ofrece unos efectos especiales notables tendiendo en cuenta que se hizo hace casi cuarenta años. Aunque ciertas imágenes que se intercalan puedan parecer confusas, es recomendable verla en más de una ocasión para entenderlas en su contexto. $\mathrm{Y}$ es precisamente este trasfondo lo que destaca en la película por encima incluso de su poderío visual. Lo que subyace tiene gran afinidad con lo que plantea H. G. WELLS en su obra Jekyll y Hide. En ambas, el científico protagonista quiere descubrir su propio yo, uno mucho más naturalista que satisfaga sus instintos más básicos y le proporcione la felicidad que su opresiva sociedad no le ofrece. Huyendo así, en definitiva, de todos aquellos artificios que siempre han condicionado su vida (la sensación continua de estar pecando, entre otros) debido a su adoctrinamiento católico. Por otro lado, la idea de que exista una especie de subconsciente común de la especie humana, que posea información relevante sobre nuestros orígenes, es realmente vanguardista a la vez que sugerente.

\section{El día de mañana, de Roland Emmerich.}

Título original: The Day After Tomorrow

Año: 2004

\section{Director: ROLAND EMMERICH}

Guión: Roland EMmERICH, JEFFrey NACHMANOFF

Música: Harald KLOSER

Reparto: DENNIS QuAID, JAKE GyllenhaAL, IAN HOLM

Género: Ciencia ficción. Acción I Catástrofes.

Sinopsis: Un meteorólogo en una base de la Antártida obtiene unos resultados alarmantes de unas perforaciones y observa como un gigantesco bloque de hielo del tamaño de un pequeño estado se suelta y cae al mar. Inmediatamente alerta a las autoridades de que todo apunta una inminente catástrofe a escala mundial. El planeta 
está abocado a una nueva era glacial provocada por los efectos del calentamiento global. Debido a que el hielo se ha derretido en los polos, los océanos han incrementado demasiado su nivel. Este exceso de agua ha trastocado completamente las corrientes marinas de las que depende el clima en la Tierra.

Aspectos técnicos: El cambio climático que congela el planeta no puede ocurrir en apenas cuatro semanas. Se trata de un proceso que tendría lugar en otras escalas de tiempo más largas, desde un par de siglos hasta miles de años. Por eso llaman la atención las corrientes de frío que congelan todo a su paso y que persiguen a los protagonistas como si de una avalancha de nieve se tratara. MichaEl Svoboda, en la sinopsis de su ensayo Cli-fi on the screen(s): patterns in the representations of climate change in fictional films [6] (2016), menciona explícitamente esta película: «Fictional works about climate change, or cli-fi, have been hailed as a new genre [...] noting the recent emergence of films that parody concerns about climate change or that depict attempts to mitigate its causes or ameliorate its effects as possibly more disastrous than climate change itself, this study recommends that researchers in the humanities and social sciences look beyond The Day After Tomorrow, which has received far more attention than any other film.»

\section{C.2 Literatura}

\section{José Miguel Gallardo}

Unidad de Teledetección Terrestre, Agencia Estatal de Meteorología (AEMET)

Escritor

La meteorología es un tema que no suele ser muy recurrente en la literatura, aunque parece que últimamente sí que está captando adeptos. Tanto es así que ya se habla de un nuevo género en cine y literatura: la ficción climática o $c l i-f i[1,4,6,7]$. Es cierto que este género hace referencia a posibles consecuencias catastróficas del cambio climático y una de las primeras obras que trata este tema es El mundo sumergido, de J. G. BALLARD (de 1962), en la que mares, pantanos y lagunas cubren la mayor parte de la Tierra. $\mathrm{El}$ aumento de la temperatura ha propiciado un clima tropical, de manera que la flora y la fauna proliferan de forma extraordinaria y el mundo parece volver al triásico. Los pocos humanos deben desplazarse en embarcaciones y sobrevivir con los escasos restos de civilización que pueden encontrar en los pisos más altos de los rascacielos ahora sumergidos.

A continuación ofrecemos una síntesis de algunos títulos más de este género:

El final de la Tierra, de Frederik Pohl y Jack Williamson (1990). Dos maestros del relato han colaborado en una historia épica del desastre y del pueblo heroico que triunfó sobre él. POHL y WILLIAMSON, en esta interesante aventura acaecida en un futuro muy posible, han realizado lo que muy pocos son capaces: tejer un tapiz de acontecimientos y personajes vivo en los detalles y memorable por el heroísmo y el sacrificio de quienes sobrevivieron a un cataclismo y a la pesadilla de sus consecuencias.

Estado de miedo, de Michael Crichton (2004). Un polémico y tenso thriller para el que el autor de Parque Jurásico se documentó cuidadosamente. CRICHTON lanza una bomba de tiempo: tras las bondades de la causa ecologista puede esconderse la mentira, la manipulación informativa y el miedo como arma infalible para controlar a la humanidad: ¿Cuánto hay de cierto en lo que leemos sobre el deterioro del planeta?

La carretera, de Cormac McCarthy (2006). Merecido premio Pulitzer en el que, en medio de un paisaje nevado y frío, un padre y su hijo buscan un lugar seguro donde vivir y donde escapar de los pocos hombres que han sobrevivido a lo que se supone una catástrofe bélica, medioambiental, o de cualquier otro tipo, lo que ha provocado que el clima sea gélido en todo el planeta.

El problema de los tres cuerpos, de Liu Cixin (2006). Este es el primer libro de una trilogía de ciencia ficción. A priori no guarda relación ni con la meteorología ni con el clima, pero plantea una serie de conflictos que invitan a la reflexión. Empieza en el contexto de la Revolución Cultural china, cuando un proyecto militar secreto envía señales al espacio para contactar con extraterrestres. Pronto, una civilización alienígena al borde de la destrucción capta la señal y comienza a planear su desembarco en la Tierra. Durante las décadas siguientes, se comunica a través de un insólito método: un extraño videojuego virtual impregnado de historia y filosofía. Pero a medida que los alienígenas empiezan a ganar a los jugadores terrícolas, se forman 
distintos bandos, unos dispuestos a dar la bienvenida a esos seres superiores y ayudarlos a hacerse cargo de un mundo tan corrupto y otros preparados para luchar contra la invasión. El resultado es una experiencia tan auténtica como reveladora sobre nuestro tiempo.

La chica mecánica, de Paolo Bacigalupi (2009). ANDERSON LAKE es uno de los pocos occidentales que ha obtenido permiso de trabajo y residencia en Tailandia. Sin embargo, la fábrica que dirige es una tapadera: su misión es descubrir la reserva de semillas no modificadas de plantas desaparecidas hace muchos años en el resto del planeta, que misteriosamente se han conservado en el aislado reino asiático, y entregarla a la multinacional biotecnológica para la cual realmente trabaja. PAOLO BACIGALUPI nos lleva al siglo XXII, un mundo donde el cambio climático ha dejado grandes estragos: casi se han agotado el petróleo, el gas y el carbón, la tracción animal ha reemplazado los motores de combustión, la ingeniería genética se aplica en cultivos, animales e incluso humanos, y las multinacionales biotecnológicas controlan la principal fuente de alimentos: las semillas transgénicas.

El año del diluvio, de Margaret Atwood (2010). La autora nos muestra en esta novela una visión posapocalíptica del mundo tras una catástrofe global y describe el horror de un mundo en el que la humanidad, en aras del progreso científico y tecnológico, no sólo altera el medio ambiente sino que se autodestruye.

Solar, de Ian McEwan (2010). MiCHAEL BEARD es un físico que recibió hace años el Premio Nobel por un descubrimiento que en los medios científicos se conoce como la combinación BEARD-EINSTEIN -y aquí comienza la feroz e irresistible ironía de MCEWAN, porque combinación implica también simbiosis, confusión-, y desde entonces se ha limitado a vivir apoltronado en sus laureles. Desde hace años no es más que un burócrata de la ciencia, un científico para quien la emoción y la aventura han quedado relegadas a la vida privada, la cabeza visible de un instituto estatal para la investigación de las energías renovables que es poco más que un artilugio político. Entre los jóvenes becarios del instituto se encuentra TOM ALDOUS, que aún se apasiona por lo que hace y tiene proyectos mucho más ambiciosos que la insignificante turbina a la que aspiran los políticos. Cuando una noche TOM lleva a BEARD a casa en su coche y conoce a PATRICE, la combinación de adulterio en las clases ilustradas y esperpento científico deviene una negra comedia de enredos, de intriga al más puro estilo de НITCHCOCK, con cadáver incluido, y aquí y ahora, en este mundo en los umbrales del gran cambio climático, del temido calentamiento global...

El ruido de un trueno, de Ray Bradbury (1952). Como tal no trata el tema del cambio climático, pero sí el del efecto mariposa. Es un cuento que transcurre en el año 2055, donde un negocio llamado Safari en el tiempo $S$. A. promete llevar a sus clientes de viaje al pasado para que puedan cazar animales prehistóricos, como el tiranosaurio. Al emprender el viaje, los cazadores son advertidos de que, para evitar la paradoja del viaje en el tiempo, deben ser muy cuidadosos de dejar todo como lo encontraron en un principio, pero nada sale como esperaban...

Otras obras no tratan directamente el tema de la climatología o la meteorología, pero una de estas dos ciencias forma parte del hilo conductor de la trama o bien la desencadena, como es el caso de «La última noche en Tremore Beach», de MiKel SANTIGO, en la que una tormenta de colosales proporciones es el arranque de una novela en la que un prestigioso compositor de bandas sonoras que, tras un traumático divorcio, se refugia en un rincón perdido de la costa de Irlanda para recuperar la inspiración. La casa de Tremore Beach, aislada en una enorme y solitaria playa, parece el lugar indicado para lograrlo. Todo parece perfecto... hasta que intuye lo contrario.

2065 de José Miguel Gallardo (2017). La novela de la que soy autor, «2065», se ubica en el Madrid de dicho año. En sí, es una obra de ficción cuyo género es la novela negra, aunque el hilo conductor de la trama es el cambio climático y está basado en proyecciones climáticas reales, en particular utilizo las características que definen el RCP 4.5 del quinto informe del IPCC para ambientar la novela (sec. 29.6.1 en la página 513 y sec. 29.6.2 en la página 514). Una de esas características es que la tecnología no progresas a pasos de gigante pero tampoco queda estancada. Dado que un alto porcentaje de la evolución de la meteorología va de la mano de los avances tecnológicos, tenía que presentar una evolución realista de dicha ciencia, por lo que estuve analizando cómo sería y cómo se comunicaría la meteorología dentro de unos 50 años aproximadamente. Sin duda, la inercia es que la meteorología determinista vaya perdiendo fuerza en pro de la probabilista, ya que aporta más información y de mejor calidad. Baste decir que si la probabilidad 
de lluvia es un $40 \%$ para un partido de fútbol lo lógico sería jugarlo, pero si una empresa puede perder millones de euros si ese mismo día llueve, la probabilidad del $40 \%$ seguro que se les antoja demasiado alta (sec. 15.10 en la página 234).

Lo lógico es pensar que con procesadores cada vez más potentes lleguemos a tener predicciones probabilistas cada vez con mejor resolución.

En «2065» varios asesinatos se ocultan tras las muertes que deja el cambio climático. Todos esos homicidios ocurren siempre con fenómenos meteorológicos adversos y ahora se acerca un huracán, Eolo, a la península ibérica. El próximo al que van a matar es un meteorólogo, ADRIÁN SALOR, que tendrá que pronosticar cuándo llegará el huracán para evitar su muerte. Así que el protagonista utiliza los SPC para calcular «cuáles son sus expectativas de vida». Su inquietud queda reflejada en el siguiente párrafo de la novela:

«Llegó la noche y Adrián se fue a descansar a casa. Sin ser capaz de concentrarse en nada, intentó distraerse mirando las previsiones de las posibles trayectorias del huracán. Según lo que podía observar en los mapas, el anticiclón de las Azores — situado sobre las islas que le prestaban su nombre- se desplazaría, con una incertidumbre media-alta, hacia el sur durante los próximos días, de forma que dejaba un espacio por el que el huracán podría llegar a la península ibérica sin obstáculos.
La incertidumbre de que EOLO finalmente se decantase por ese camino era media-baja. ADRIÁN encontraba cierta ironía en esos datos, pues la posibilidad que tenía de morir en los próximos días era media-baja, y se le antojaba excesivamente grande tratándose de un juego a vida o muerte, por lo que siguió consultando mapas con el fin de mejorar el pronóstico».

\section{C.3 Lecturas recomendadas}

Además de las referencias ofrecidas que abordan el novedoso género de la Cli-Fi [4, 6, 7], ÁNGELA CANTALEJo, en el suplemento Tentaciones de El País de 11-10-2015 presenta, con un lenguaje sencillo, la CliFi como la literatura que predice el cambio climático [1].

El Portal CienciaYFicción de Víctor Vila es un sitio web que, consiguiendo un equilibrio entre el rigor científico y la accesibilidad a un amplio público, informa de temas propios de la ciencia-ficción y de los márgenes vanguardistas de la ciencia abordando, desde el cine y la literatura, hasta las investigaciones más recientes en nanorobótica [9]. 


\section{C.4 Referencias}

[1] Cantalejo, Ángela. Cli-Fi: la literatura que predice el cambio climático. Oct. de 2015. URL: https : / / elpais . com / elpais / 2015 / 10 / 11 / tentaciones / 1444559211 _ 036190 . html (citado en páginas 962, 964).

[2] EdWARDS, Roger. Bat-eating Supercell (SPC Cool Image). 2006. URL: http : / / www . spc . noaa. gov/ coolimg/batrad/ index.html (visitado 19-03-2018) (citado en página 960 ).

[3] Feynman, Richard P, Leighton, Robert B y SANDS, Matthew. The Feynman lectures on physics, Vol. I: The new millennium edition: mainly mechanics, radiation, and heat. Volumen 1. Basic books, 2011 (citado en página 959).

[4] Johns-Putra, Adeline. "Climate change in literature and literary studies: From clifi, climate change theater and ecopoetry to ecocriticism and climate change criticism". En: Wiley Interdisciplinary Reviews: Climate Change 7.2 (2016), páginas 266-282. DOI: 10.1002/wcc. 385 (citado en páginas 962, 964).

[5] LANDAU, L D y Lifshitz, E M. "Mechanics, vol. 1". En: Course of theoretical physics 3 (1976) (citado en página 959).

[6] Svoboda, Michael. "Cli-fi on the screen (s): patterns in the representations of climate change in fictional films". En: Wiley Interdisciplinary Reviews: Climate Change 7.1 (2016), páginas 43-64. DOI: 10.1002/wcc . 381 (citado en páginas 962, 964).

[7] Tuhus-Dubrow, Rebecca. "Cli-fi: Birth of a genre". En: Dissent 60.3 (2013), páginas 58-61 (citado en páginas 962, 964).

[8] VARela, Javier. El día que los peces llegaron caídos del cielo. La Verdad. 2014. URL: http : / / www . laverdad . es / murcia / rc/20140509/sociedad/peces-caiancielo-20140508154649 .html (visitado 17-05-2014) (citado en página 960).

[9] Víctor Vila. Portal CienciaYFicción. 2018. URL: http : / / www . portalcienciayficcion.com/ (visitado 19-03-2018) (citado en página 964). 